\title{
Synthesis of densely functionalized enantiopure indolizidines by ring-closing metathesis (RCM) of hydroxylamines from carbohydrate-derived nitrones
}

\author{
Marco Bonanni, Marco Marradi, Francesca Cardona, Stefano Cicchi and
} Andrea Goti

\section{Full Research Paper}

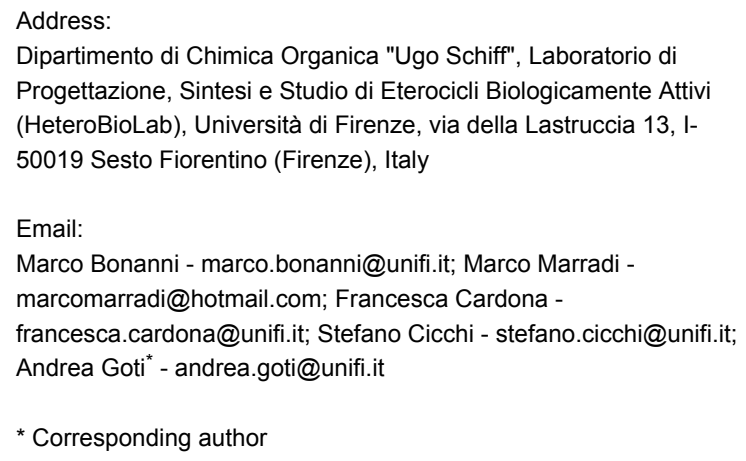

Beilstein Journal of Organic Chemistry 2007, 3, No. 44. doi:10.1186/1860-5397-3-44

Received: 17 October 2007

Accepted: 12 December 2007

Published: 12 December 2007

(C) 2007 Bonanni et al; licensee Beilstein-Institut

License and terms: see end of document.

\begin{abstract}
Background

Indolizidine alkaloids widely occur in nature and display interesting biological activity. This is the reason for which their total synthesis as well as the synthesis of non-natural analogues still attracts the attention of many research groups. To establish new straightforward accesses to these molecules is therefore highly desirable.
\end{abstract}

\section{Results}

The ring closing metathesis (RCM) of enantiopure hydroxylamines bearing suitable unsaturated groups cleanly afforded piperidine derivatives in good yields. Further cyclization and deprotection of the hydroxy groups gave novel highly functionalized indolizidines. The synthesis of a pyrroloazepine analogue is also described.

\section{Conclusion}

We have developed a new straightforward methodology for the synthesis of densely functionalized indolizidines and pyrroloazepine analogues in 6 steps and 30-60\% overall yields from enantiopure hydroxylamines obtained straightforwardly from carbohydrate-derived nitrones. 


\section{Background}

Indolizidine alkaloids have widespread occurrence in nature. They can be found in widely different organisms such as bacteria, fungi, higher plants, invertebrates and vertebrates.[1] For instance, the plant-derived polyhydroxylated indolizidines are well known as potent glycosidases inhibitors, and for this reason they are potential therapeutic agents. [2-4] A great deal of research is still devoted to the structural elucidation of these alkaloids as well as to their total syntheses. [5-18]

We accomplished the total syntheses of some indolizidine alkaloids and of several non-natural analogues employing chiral nitrones as key intermediates, either as dipolarophiles in 1,3dipolar cycloaddition chemistry $[19,20]$ or as electrophiles in the addition of organometallic reagents. [21,22] Recently, we developed a general protocol for the synthesis of $\alpha, \alpha^{\prime}$-disubstituted enantiopure hydroxylamines 1 through the stereoselective double addition of an excess of a Grignard reagent to $C$-phenyl$N$-erythrosylnitrone 2 (Scheme 1).[23] With this methodology, several symmetrically $\alpha, \alpha^{\prime}$-disubstituted hydroxylamines $\mathbf{1}$ were afforded.

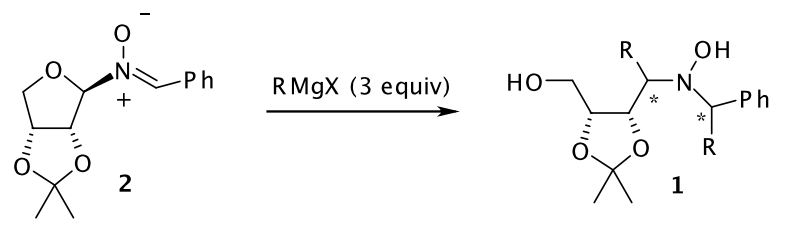

Scheme 1: Synthesis of symmetrically $\alpha, \alpha^{\prime}-$ disubstituted hydroxylamines 1.

An alternative protocol for the synthesis of unsymmetrically $\alpha, \alpha^{\prime}$-disubstituted hydroxylamines $\mathbf{3}$, resulting from the sequential addition of two different Grignard reagents, was also developed in a stepwise process, based on an addition-oxidation-addition sequence starting from $\mathrm{N}$-glycosylhydroxylamine 4 (Scheme 2).[24]

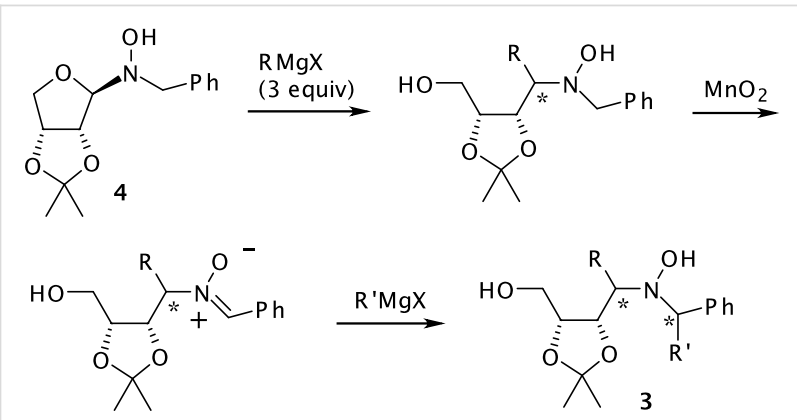

Scheme 2: Synthesis of unsymmetrically $\alpha, \alpha^{\prime}$-disubstituted hydroxylamines 3 .
Addition of unsaturated Grignard reagents afforded synthetically useful hydroxylamine intermediates, which may serve as substrates for nitrogen ring forming reactions. We report in this article a straightforward access to indolizidine derivatives and a pyrroloazepine analogue through a key ring closing metathesis (RCM) of sugar derived hydroxylamines $\mathbf{1}$ and $\mathbf{3}$ bearing suitable unsaturated substituents at the $\alpha$ and $\alpha^{\prime}$ positions.

\section{Results and discussion}

Unsymetrically $\alpha, \alpha^{\prime}$-disubstituted hydroxylamines 5 and $\mathbf{6}$ (Scheme 3) were synthesized according to our recently reported procedure based on the addition-oxidation-addition sequence starting from $N$-glycosylhydroxylamine 4 (Scheme 2),[24] while hydroxylamine 7 was obtained using an excess of allylmagnesium bromide in the addition to $C$-phenyl- $N$-erythrosylnitrone 2.[23] It should be noted that the stepwise process furnishes configurationally diversified stereoisomers at the benzylic position (e. g. 5 and 6), due to a high stereoselectivity in the first addition step but a poor one in the second.[24] Specifically, $\mathbf{5}$ was isolated as the major isomer from a ca 2:1 diastereomeric mixture, while $\mathbf{6}$ was obtained from an equimolecular mixture with its diastereoisomer.[24] Assignment of configuration has been secured by comparison with the double adducts of the one-pot process and by careful NMR studies of the final cyclic products after RCM. The scarce stereoselectivity of the second addition in the stepwise process, giving rise to two diastereoisomers, opens the way to the synthesis of diastereomeric indolizidines.

The RCM reaction has been successfully employed for the synthesis of polyfunctional indolizidines. [25-29] In order to accomplish successfully the key RCM reactions, preliminary protection of the hydroxylamine $\mathrm{OH}$ group was required. Selective acetylation of hydroxylamines 5-6 was achieved with acetic anhydride in THF at room temperature, while for hydroxylamine 7 it was necessary to heat the mixture at reflux. No acetylation of the primary alcohol was observed under these conditions.

Ring-closing metathesis (RCM) of $O$-acetylhydroxylamines 8-10 using the second generation Grubbs' catalyst 11 [30] in refluxing $\mathrm{CH}_{2} \mathrm{Cl}_{2}$ afforded compounds 12-14 in nearly quantitative yields (Scheme 3). However, compounds 12 and 13 suffered from low stability and for this reason the crude reaction mixtures were directly employed in the following steps.

Identity of compounds $\mathbf{1 2}$ and $\mathbf{1 3}$ was firmly established after their transformation into the corresponding amines and further elaboration. After deacetylation with $\mathrm{KHCO}_{3}$, in situ reduction of the N-O bond with zinc dust afforded tetrahydropyridines $\mathbf{1 5}$ 


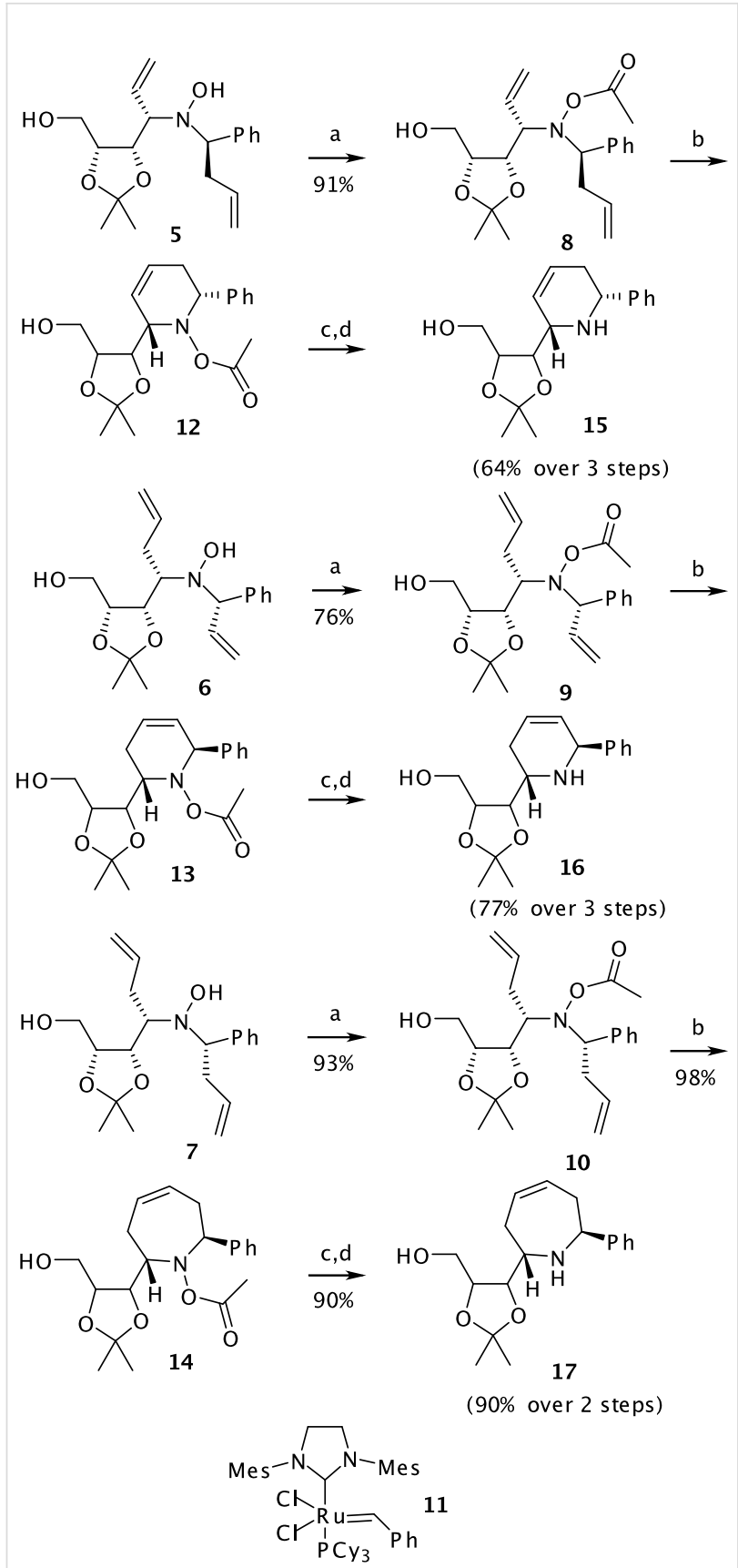

Scheme 3: Synthesis of piperidines 15-16 and azepine 17. Reagents and conditions: a) $\mathrm{Ac}_{2} \mathrm{O}, \mathrm{THF}, 1 \mathrm{~h}$, rt for 8 and 9 , reflux for 10 ; b) $2^{\text {nd }}$ generation Grubbs' catalyst 11 (5 mol\%), $\mathrm{CH}_{2} \mathrm{Cl}_{2}$, reflux, $5.5 \mathrm{~h} ; \mathrm{c}$ ) $\mathrm{KHCO}_{3}, \mathrm{MeOH}, \mathrm{rt}, 12 \mathrm{~h}$; d) $\mathrm{Zn}, \mathrm{AcOH}$, rt, 2 h.

and 16 (Scheme 3). Analogously, deprotection of $\mathbf{1 4}$ and in situ reduction with zinc dust gave tetrahydroazepine 17 (Scheme 3).

Cyclization to give the fused 5-membered ring was achieved by treatment of compounds 15-17 with trifluoromethanesulfonic anhydride in pyridine at room temperature (Scheme 4). The structure of protected indolizidines 18-19 and of pyrro-

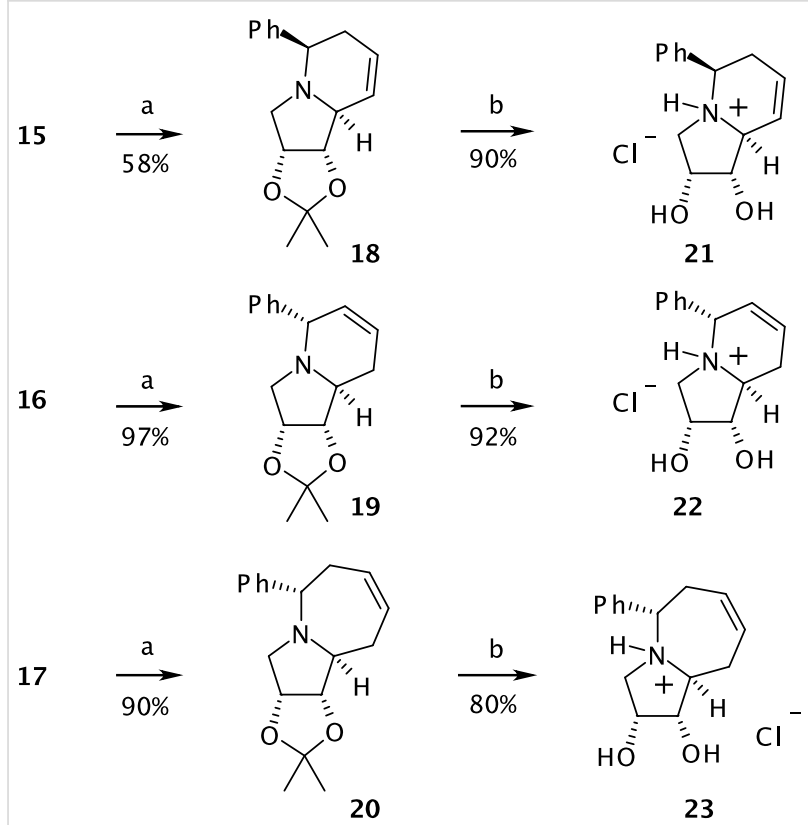

Scheme 4: Synthesis of indolizidines 21-22 and pyrroloazepine 23 Reaction conditions: a) $\mathrm{Tf}_{2} \mathrm{O}, \mathrm{Py}, \mathrm{rt}, 2 \mathrm{~h}$; b) Conc. $\mathrm{HCl}, \mathrm{MeOH}, \mathrm{rt}, 2 \mathrm{~h}$.

loazepine 20 (and therefore of compounds 12-14) was unambiguously determined by spectral data, including 2D COSY and 1D NOESY experiments (See Experimental).

Final deprotection of $\mathbf{1 8}-\mathbf{2 0}$ with an acidic solution of $\mathrm{MeOH}$ afforded protonated indolizidines 21-22 in good yields (Scheme 4). Analogously, deprotection of $\mathbf{2 0}$ gave pyrrolazepine 23, which displayed good inhibition of $\alpha$-glucosidase from yeast (90\% at $1 \mathrm{mM})$.[23] Compounds $\mathbf{1 7}$ and $\mathbf{2 3}$, containing an azepane moiety, might be of biological interest as shown recently. [31-35] Indolizidines 21-22 differ in the absolute configuration at $\mathrm{C} 5$ and in the position of the double bond, illustrating the structural diversity attainable with this strategy. It should be noted that similar dihydroxyhexahydroindolizines maintained glucosidase inhibition activity in analogy to the completely unsaturated compounds.[22] Moreover, it has been recently proved that dihydroxypyrrolidines bearing aromatic rings have interesting antitumor activities. [36,37] Work is underway to evaluate the biological activity of the newly synthesized compounds. In addition, the presence of a double bond should allow the introduction of additional hydroxy groups or other functionalities by appropriate elaboration.

\section{Experimental}

[See Supporting Information File 1 for full experimental data] 


\section{Supporting Information}

\section{Supporting Information File 1}

Synthesis of densely functionalized enantiopure indolizidines by ring-closing metathesis (RCM) of hydroxylamines from carbohydrate-derived nitrones. Experimental Sections. Experimental procedures, characterization of new compounds. [http://www.beilstein-journals.org/bjoc/content/ supplementary/1860-5397-3-44-S1.pdf]

\section{Acknowledgments}

We thank Cassa di Risparmio di Firenze for granting a 400 $\mathrm{MHz}$ spectrometer. Maurizio Passaponti and Brunella Innocenti (Università di Firenze) are acknowledged for technical assistance. We thank INSTM for partially financing a research grant to one of us (MB)

\section{References}

1. Michael, J. P. Simple indolizidine and quinolizidine alkaloids. In The Alkaloids; Cordell, G., Ed.; Academic Press: San Diego, 2001; Vol. 55, pp 91-258.

2. Watson, A. A.; Fleet, G. W. J.; Asano, N.; Molyneux, R. J.; Nash, R. J. Phytochemistry 2001, 56, 265-295. doi:10.1016/S0031-9422(00) 00451-9

3. Asano, N. Glycobiology 2003, 13, 93R-104R. doi:10.1093/glycob/ cwg090

4. Robina, I.; Moreno-Vargas, A. J.; Carmona, A. T.; Vogely, P. Curr. Drug Metab. 2004, 5, 329-361. doi:10.2174/1389200043335513

5. Michael, J. P. Nat. Prod. Rep. 2007, 24, 191-222. doi:10.1039/ b509525p

And previous review in the series of annual reviews on indolizidine and quinolizidine alkaloids.

6. Torres-Sanchez, M. I.; Borrachero, P.; Cabrera-Escribano, F.; GomezGuillen, M.; Angulo-Alvarez, M.; Alvarez, E.; Favre, S.; Vogel, P. Tetrahedron: Asymmetry 2007, 18, 1809-1827. doi:10.1016/ j.tetasy.2007.08.001

7. Carmona, A. T.; Fuentes, G.; Robina, I.; Rodriguez Garcia, E.; Demange, R.; Vogel, P.; Winters, A. L. J. Org. Chem. 2003, 68, 3874-3883. doi:10.1021/jo026688a

8. Reymond, J. L.; Pinkerton, A.; Vogel, P. J. Org. Chem. 1991, 56, 2128-2135. doi:10.1021/jo00006a031

9. Hanessian, S.; Therrien, E.; Warrier, J. S.; Charron, G. Heterocycles 2006, 70, 461-476.

10. Langlois, N.; Le Nguyen, B. K.; Retailleau, P.; Tarnus, C.; Salomon, E. Tetrahedron: Asymmetry 2006, 17, 53-60. doi:10.1016/ j.tetasy.2005.11.017

11. Socha, D.; Jurczak, M.; Chmielewski, M. Carbohydr. Res. 2001, 336 315-318. doi:10.1016/S0008-6215(01)00265-8

12. Izquierdo, I.; Plaza, M. T.; Robles, R.; Mota, A. J. Eur. J. Org. Chem. 2000, 2071-2078. doi:10.1002/1099-0690(200006) 2000:11<2071::AID-EJOC2071>3.0.CO;2-A
13. Vyavahare, V. P.; Chakraborty, C.; Maity, B.; Chattopadhyay, S.; Puranik, V. G.; Dhavale, D. D. J. Med. Chem. 2007, 48, 5519-5523. doi:10.1021/jm070660f

14. Chen, M.-J.; Tsai, Y.-M. Tetrahedron Lett. 2007, 48, 6271-6274. doi:10.1016/j.tetlet.2007.07.021

15. Pandey, G.; Dumbre, S. G.; Pal, S.; Khan, M. I.; Shabab, M. Tetrahedron 2007, 63, 4756-4761. doi:10.1016/j.tet.2007.03.085

16. Karanjule, N. S.; Markad, S. D.; Dhavale, D. D. J. Org. Chem. 2006, 71, 6273-6276. doi:10.1021/jo060823s

17. Song, L.; Duesler, E. N.; Mariano, P. S. J. Org. Chem. 2004, 69, 7284-7293. doi:10.1021/jo040226a

18. Sletten, E. M.; Liotta, L. J. J. Org. Chem. 2006, 71, 1335-1343. doi:10.1021/jo051792o

19. Brandi, A.; Cardona, F.; Cicchi, S.; Cordero, F. M.; Goti, A. Curr. Trends. Org. Synth. 1999, 213-220.

20. Cordero, F. M.; Pisaneschi, F.; Gensini, M.; Goti, A.; Brandi, A. Eur. J. Org. Chem. 2002, 1941-1951. doi:10.1002/1099-0690(200206) 2002:12<1941::AID-EJOC1941>3.0.CO;2-T

21. Cardona, F.; Goti, A.; Brandi, A. Eur. J. Org. Chem. 2007, 1551-1565. doi:10.1002/ejoc.200600633 And references cited therein

22. Cardona, F.; Moreno, G.; Guarna, G.; Vogel, P.; Schuetz, C.; Merino, P.; Goti, A. J. Org. Chem. 2005, 70, 6552-6555. doi:10.1021/ jo0509408

23. Bonanni, M.; Marradi, M.; Cicchi, S.; Faggi, C.; Goti, A. Org. Lett. 2005, 7, 319-322. doi:10.1021/ol047691e

24. Bonanni, M.; Marradi, M.; Cicchi, S.; Goti, A. Synlett, in press.

25. Ovaa, H.; Stragies, R.; van der Marel, G. A. Chem. Commun. 2000, 1501-1502. doi:10.1039/b004106h

26. Pandit, U. K.; Overkleeft, H. S.; Borer, B. C.; Bieräugel, H. Eur. J. Org. Chem. 1999, 959-968. doi:10.1002/(SICl)1099-0690(199905) 1999:5<959::AID-EJOC959>3.0.CO;2-K

27. Deiters, A.; Martin, S. F. Chem. Rev. 2004, 104, 2199-2238. doi:10.1021/cr0200872

28. Wakamatsu, H.; Sato, Y.; Fujita, R.; Mori, M. Adv. Synth. Catal. 2007, 349, 1231-1246. doi:10.1002/adsc.200600539

29. Murray, A. J.; Parsons, P. J.; Hitchcock, P. Tetrahedron 2007, 63, 6485-6492. doi:10.1016/j.tet.2007.03.103

30. Scholl, M.; Ding, S.; Lee, C. W.; Grubbs, R. H. Org. Lett. 1999, 1, 953-956. doi:10.1021/ol990909q

31. Li, H.; Zhang, Y.; Vogel, P.; Sinay, P.; Bleriot, Y. Chem. Commun. 2007, 183-185. doi:10.1039/b610377d

32. Li, H.; Schuetz, C.; Favre, S.; Zhang, Y.; Vogel, P.; Sinay, P.; Bleriot, Y. Org. Biomol. Chem. 2006, 4, 1653-1662. doi:10.1039/b518117h

33. Bleriot, Y.; Mallet, J.-M.; Zhang, Y.; Rodriguez-Garcia, E.; Vogel, P.; Mari, S.; Jimenez-Barbero, J.; Sinay, P. Heterocycles 2004, 64, 65-74.

34. Li, H.; Bleriot, Y.; Mallet, J.-M.; Rodriguez-Garcia, E.; Vogel, P.; Zhang, Y.; Sinay, P. Tetrahedron: Asymmetry 2005, 16, 313-319. doi:10.1016/j.tetasy.2004.12.005

35. Lertpibulpanya, D.; Marsden, S. P. Org. Biomol. Chem. 2006, 4, 3498-3504. doi:10.1039/b608801e

36. Fiaux, A.; Popowycz, F.; Favre, S.; Schütz, C.; Vogel, P.; GerberLemaire, S.; Juillerat-Jeanneret, L. J. Med. Chem. 2005, 48, 4237-4246. doi:10.1021/jm0409019

37. Favre, S.; Fiaux, H.; Schutz, C.; Vogel, P.; Juillerat-Jeanneret, L.; Gerber-Lemaire, S. Heterocycles 2006, 69, 179-192. 


\section{License and Terms}

This is an Open Access article under the terms of the Creative Commons Attribution License

(http://creativecommons.org/licenses/by/2.0), which permits unrestricted use, distribution, and reproduction in any medium, provided the original work is properly cited.

The license is subject to the Beilstein Journal of Organic Chemistry terms and conditions:

(http://www.beilstein-journals.org/bjoc)

The definitive version of this article is the electronic one which can be found at:

$\underline{\text { doi:10.1186/1860-5397-3-44 }}$ 